Molina-Luque, Fidel (2021). El nuevo contrato social entre generaciones. Elogio de la profiguración. Madrid: Los libros de la Catarata. ISBN 978-84-13521-99-2, 174 páginas.

\title{
Paquita Sanvicén-Torné
}

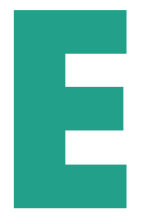

1 escenario actual provocado por la COVID-19 ha hecho reaparecer vivamente el concepto contrato social en los medios de comunicación, en la voz de líderes sociales y políticos. Los argumentos a favor de la necesidad de un nuevo contrato social son recurrentes, especialmente con la mirada puesta en el lastre económico y de desigualdad que ha comportado la pandemia. A la vez, con todo lo vivido en estos meses, permanece más latente si cabe la mirada social, las llamadas a recuperar cuanto antes la relación activa jóvenes-mayores, descrita con diferente nomenclatura: pacto entre generaciones, sutura intergeneracional, aprendizaje entre generaciones, vinculo intergeneracional, diálogo intergeneracional, etc.

Es en ese escenario de sociedades y espacios ciudadanos donde las personas educan y se educan, de pasado, presente y de futuro, que destacamos la oportunidad y el acierto de la aportación teórica y reflexiva del Doctor Fidel Molina-Luque en su ensayo El nuevo contrato social entre generaciones. Elogio de la profiguración. Imprescindible sin duda para pensar sobre qué tipo de sociedad estamos construyendo realmente y repensarnos, en lo individual y lo colectivo, habitantes activos como somos de sociedades hiperconectadas, demográficamente complejas, de riesgos y encrucijadas locales y globales. Finalista del IV Premio de Ensayo de La Catarata, cumple con creces la finalidad marcada por la editorial: «estimular la generación de ideas y análisis útiles para comprender la realidad desde una perspectiva crítica». Estimulante, fecundo, analítico, riguroso, útil, necesario, amable, cercano, son adjetivos que definen el trabajo del Doctor Molina-Luque. A partir de su larga y reconocida trayectoria activa en la ciencia sociológica, como pensador, docente, investigador, generador de proyectos, divulgador, etc., profundiza en su compromiso científico y social dándole forma teórica y expositiva, con esa cualidad de espíritu que le caracteriza y que Wright Mills definió como «imaginación sociológica», observando, analizando la realidad social y las interrelaciones que se dan en ella.

Aunque el libro ha sido finalizado y publicado en pleno tiempo de pandemia y la reflexión sobre sus afectaciones y retos presentes y futuros aparecen en diferentes capítulos, no es una propuesta resultante del escenario social provocado por la COVID-19. Tampoco es la primera aportación del autor sobre el tema que desarrolla. El nuevo contrato social entre generaciones. Elogio de la profiguración es el resultado de un largo periodo de análisis que había ido viendo la luz hasta ahora de manera fragmentada en artículos,

1 Paquita Sanvicén-Torné, Universitat de Lleida, paquita.sanvicen@udl.cat. 
talleres y conferencias (2017, 2019, 2020a, 2020b). Por ello, su experiencia acumulada de investigaciones y proyectos sobre inclusión educativa, prevención y mediación de conflictos, comunidades de aprendizaje, interculturalidad, aprendizaje servicio, envejecimiento activo se ve claramente reflejada de principio a fin.

Molina-Luque bebe asimismo de una extensa nómina de fuentes. En los diferentes apartados va mostrando con que compone sus cimientos a través de un sólido y exhaustivo recorrido en el que une aportaciones clásicas y contemporáneas, de la sociología, filosofía, antropología y pedagogía, especialmente. Las referencias a las aportaciones más actuales en los diversos campos que trata se suman a las de Durkheim, Simmel, Tönnies, Aristóteles, Sócrates, Freire, Castells, Bauman, Giddens, Beck, Habermas, Norbert Elias... formando un consistente armazón que supera las doscientas referencias.

Situado a hombros de todos ellos, indaga en la tipología de la socialización de Margared Mead. Molina-Luque actualiza y complementa su propuesta como antropóloga cultural pensada en y para el contexto de mediados del siglo pasado. Mead distinguía entre sociedades de cultura postfigurativa; cofigurativa y prefigurativa. Para esta segunda década del siglo XxI, Molina-Luque incorpora la socialización profigurativa con la cual «se auna la voluntad educativa en pos de la "figuración"», conjuntamente, para enseñar-aprender colaborativamente, de manera dialógica. (...) Es sin duda una teoría win-win con perspectiva de futuro, a lo largo y a lo ancho de la vida, acorde con los objetivos de sostenibilidad, equilibrio y bienestar social: «un tipo de socialización conjunta, colaborativa, de manera dialógica y no necesariamente jerarquizada, entre las diversas generaciones (...) Se trata de poder de manifiesto la responsabilidad intergeneracional: las relaciones solidarias entre generaciones, entre ancianos y jóvenes, en una socialización entramada, transversal y holística» (p.73).

La temática subyacente — la relación vital, emocional y educativa entre mayores y jóvenes — no es de nuevo cuño, pero faltaba una teorización de mirada holística y una denominación conceptual desde la mirada sociológica. Molina-Luque ha llenado de contenido esos vacíos innovando sobre lo preexistente. «Si algo no se nombra no existe», nos recuerda (2020a). Por ello, crea el neologismo Profiguración para identificar teóricamente la interdependencia intergeneracional. La realidad es cambiante y por ello la labor de un teórico social es revisar las teorías anteriores, analizarlas, mejorarlas, renovándolas y actualizándolas. Ese es el resultado reflejado en el libro que reseñamos.

El autor escribe en una de sus primeras notas a pie de página «en la pragmática consideramos los actos de habla, sobretodo como actos perlocutivos; es decir situaciones que al pronunciar algo implica llevarlo a cabo, conjuntamente (quien lo dice y quien escucha): si hablamos de paz, de calma, de diálogo, de convivencia, probablemente estemos ya pacificando, calmando dialogando, conviviendo. Si hablamos de 'profiguración', estaremos 'profigurando', estableciendo relaciones respetuosas, complementarias y enriquecedoras entre generaciones... con el ánimo de implicar, además, una acción integradora de socialización intergeneracional. Es el poder de las palabras» (p. 12-13). El libro en su conjunto es el fiel reflejo de esa idea: el poder de las palabras, no solo las técnicas y complejas, sino también las que surgen de la proximidad y el cariño, de la sabiduría y oralidad que va pasando de generación en generación.

De principio a fin, el relato del autor es coherente con la teoría que desarrolla. La «profiguración» hace referencia a la buena relación, influencia, reconocimiento y legado en positivo de las experiencias y saberes entre las generaciones. Por ello, a lo largo del texto, no solo aparece la voz y la palabra del sociólogo, teórico y persona que lo escribe, sino también las de sus progenitores y, de manera intermitente, de sus 
descendientes. Palabras, gestos y memoria revivida y analizada desde el presente, sobre las que reflexiona compartiendo su propio proceso de construcción y aprendizaje humano de niño, joven y adulto. Este es uno de los hilos conductores principales y, sin duda, de los valores del texto y de la teoría: las personas, las vidas y las aportaciones sobre las que se van modelando, que las hacen pensar y actuar al tiempo que las van uniendo.

En ese sentido, de manera expresa, las ideas con que presenta cada uno de los cinco capítulos del libro son «dichos» populares: El amor es como un chicle; Una cosa es predicar y otra dar trigo; No es más limpio el que más limpia sino el que menos ensucia; Más puede la miel que la hiel; No es más rico el que más tiene, sino el que menos necesita.

«El amor es como un chicle» introduce el primer capítulo dedicado a la reflexión teórica y sociológica sobre el amor como fenómeno social, con componentes sociales. El subtitulo lo dice ya todo: «extensiones del cariño y del queren». Se analizan aportaciones clásicas d'Eric From repasando los aspectos que propician el amor verdadero y los que lo obstaculizan. Aunque trata sus diferentes facetas, se hace hincapié en el carácter de construcción social que tiene y como fenómeno y sentimiento entendido en sus dimensiones sociales: amistad, sociabilidad, solidaridad, fraternidad. Analiza la necesidad del amor en la trayectoria vital de las personas, de todas las edades, base también para la convivencia y el entendimiento mutuos. El autor dedica un interesante apartado a profundizar en los aspectos que van marcando en el tiempo, las trayectorias, los «cursos de la vida». Cursos de vidas hechos de evolución en tiempo y espacio, de momentos cruciales, de transiciones vitales al paso de una edad a otra que implica una u otra identificación social. Vidas que se construyen en procesos de socialización con toda su complejidad unos con otros, al lado de los otros. El valor que aporta la profiguración es que el recorrido avance por caminos y vías de amor verdadero, amistad, fraternidad y solidaridad.

El segundo, «una cosa es predicar y otra dar trigo» es un capítulo clave. Desarrolla, descompone y recompone dos de los conceptos que atraviesan la obra: educación y socialización. Molina-Luque vertebra un interesante repaso a la evolución en el tiempo de la concepción del papel y labor de la escuela como consecuencia de los cambios sociales. Fundamenta que la educación es social, continua a lo largo de la vida, que no se da solo en el ámbito escolar formal sino vertebrada en un proceso de socialización continuado en los diferentes contextos que vivimos. Merece especial atención sus constataciones sobre la situación en pandemia y los retos metodológicos y de contenidos del sistema educativo. Destacamos una idea: «a pesar de todas esas posibilidades bienvenidas que permiten y facilitan las TIC y el Internet de las cosas, nada puede sustituir las relaciones personales entre los alumnos (pares) y los maestros, ni las tutorías personalizadas. El conocimiento, las competencias, los valores y las emociones se desarrollan (se aprenden, se enseñan y se 'practican') en la interrelación». «(...) la COVID-19 ha puesto de manifiesto la necesidad de modelos comunitarios». (p.58; 60).

Con la mirada puesta en el escenario futuro, Molina-Luque dedica un apartado a argumentar la idoneidad de tres Alternativas formativas y socializadoras al modelo escolar actual, que deberá renovarse sin duda: Comunidades de aprendizaje; Planes educativos de entorno y el Aprendizaje Servicio - Aprendizaje Basado en la Comunidad (ApS). Tres modelos avalados por evidencias científicas de éxito que aúnan el trabajo en red, la concepción de la educación como un proceso colaborativo centrado en las personas, superador de desigualdades, y de transformación en positivo y de bienestar social. 
Desarrolla la relación «Profiguración, curiosidad y educación: el amor por la sabiduría intergeneracional» demostrando la necesaria relación biyectiva entre jóvenes y mayores. Molina-Luque defiende, la necesidad de «repensar la educación dentro y fuera de la escuela, en el marco de la profiguración, aprovechando las interrelaciones intergeneracionales» (p.74) y la sabiduría intergeneracional (p.77). Para él es una necesaria acción educativa para evitar el edadismo latente del cual nadie está a salvo. Citando Butler (1969) nos recuerda esta constatación obvia, aunque a menudo no seamos conscientes de ella «a diferencia de otros prejuicios como el racismo o el sexismo, el edadismo afecta a todos (...) mientras otros '-ismos' señalan a subgrupos particulares, todo el mundo tiene como perspectiva envejecer». (p.75). Una acción educativa que debe prepararse y pensarse. Por ello, remarca: «los beneficios de los programas intergeneracionales no se logran simplemente haciendo que las generaciones se encuentren, sino que han de responder a necesidades reales de las personas y de las comunidades: tienen que estar bien diseñados, gestionados y planificados». (p.76).

El tercero intitulado «no es más limpio el que más limpia sino el que menos ensucia», trata sobre la sostenibilidad del planeta centrándose explícitamente en los Objetivos de Desarrollo Sostenible la Agenda 2030, haciendo hincapié en la responsabilidad de conjunto de la sociedad en algo que nos compete, y afecta, mucho. Entrando el análisis en el mundo actual globalizado, lo desarrolla a partir de una afirmación inicial categórica: «decir ambiental o ecológico es decir 'humano' y por tanto también 'social'» (p. 80). Del capítulo destaca el desarrollo de conceptos tan valiosos en contenido como poco utilizados en las aulas: acrecimiento, alargascencia, haciéndose eco de reivindicaciones actuales de grupos de presión ecologistas. Acrecimiento y alargascencia se contraponen con la práctica del consumo febril, el desechar por desechar y la obsolescencia programada a la que estamos ya acostumbrados sin protestar. El autor se refiere también a la sostenibilidad social, unida a la ambiental. A partir de sus investigaciones en Rapa Nui (2020b) defiende la emergencia de pensar en la sostenibilidad de las costumbres, culturas, lenguas, maneras de hacer. Ensambla con todo ello las aportaciones positivas de la profiguración. La sostenibilidad del planeta y de nosotros mismos solo es posible con el consumo racional y el reaprovechamiento, con la desaceleración, con la calma, con el disfrute de los momentos en buena compañía y con una buena conversación. De alguna manera, volver la mirada, para pensar, a las prácticas y hábitos sostenibles de nuestros abuelas y abuelos.

El cuarto «más puede la miel que la hiel» desarrolla conceptos clave: convivencia, conflicto y violencia. Cabe destacar la disección de diferentes perspectivas y paradigmas sociológicos, del significado, composición, elementos y acciones — reales y atribuidas — del conflicto. Reiterando lo ya sabido, pero frecuentemente olvidado: el conflicto es social, no es negativo en sí mismo, conflicto y violencia no son sinónimos. Trata con detalle diferentes teorías y tipologías del conflicto, haciendo énfasis en la acción comunicativa de Habermas (p. 108). Experto especialista en mediación y gestión de conflictos, aporta afirmaciones categóricas, imprescindibles: «la resolución de conflictos tiene como base fundamental la negociación» y, caso que no sea posible, llega la mediación que «tiene como misión facilitar el diálogo, la construcción de alternativas, el consenso y el acuerdo entre las partes del conflicto, pero no impone ni dictamina la solución (...)». «Es la gestión y la transformación del conflicto lo que acabará de dar el matiz positivo o negativo a la situación conflictiva». (109-110). Igualmente es contundente con el tratamiento de la violencia en general y en las interacciones sociales: racismo, clasismo, machismo, edadismo: «la violencia no resuelve ningún conflicto, la violencia solo genera más violencia y profundiza el dolor, las desigualdades e injusticias». (p.113). 
Plantea el trabajo desde la profiguración, no solo para superar el edadismo por lo que supone de valorar la diferencia de edades y sus aportaciones mutuas, sino también para tratar las violencias, como la de género, desde un trabajo de escucha y de diálogo activo intergeneracional. Profundiza en ello a partir de constataciones diversas con sentido. Destacamos algunas: el papel fundamental del diálogo, la conversación, la comunicación; el interés de las normas, las reglas consensuadas y acordadas; el cuidado de las emociones; la objetivación del conflicto y el rechazo a cualquier solución que pase por la violencia.

El quinto «no es más rico el que más tiene, sino el que menos necesita» trata de la felicidad. La felicidad bien entendida: «la felicidad es un concepto a la vez individual y social» (p.145). Crítico en ese sentido con el predominio de un enfoque restrictivo o naif de la psicología positiva, desde la filosofía y la sociología el autor reflexiona sobre los componentes sociales de la felicidad o infelicidad, de la «obligación social» de ser feliz o de demostrar serlo, aun no siéndolo. La identificación de los miedos, dolores y tristezas le sirven para alertar sobre los miedos actuales que impactan en la profiguración: «la vejez, la enfermedad y la muerte (...) el proceso de individuación ha radicalizado los temores dirigidos al propio yo y a la precariedad del cuerpo». (p.137). Habitamos en sociedades de riesgo en las cuales «la incertidumbre vivida como amenaza, genera sufrimiento y temor (...) tristeza (...) emociones que se ven desde lo psíquico pero son profundamente sociales». (p. 139-141). Al análisis de los miedos y temores, Molina-Luque contrapone el del bienestar, calidad de vida y buen vivir. Merece atención especial el amplísimo trabajo analítico y relacional de éstos tres sensaciones vitales vinculadas con la sensación de felicidad y a los tipos de felicidad existentes (p.154-155). Análisis del significado del «buen vivir» humanista que propugna, más allá del imaginario social en el contexto de la sociedad actual de capitalismo salvaje e hiperconsumo instantáneo. «Señala la necesidad perentoria y la alegría de la interdependencia, que no puede tener otro sentido y otro (pasado), presente y futuro que la profiguración». (p.149). El autor argumenta ampliamente la contundencia de sus palabras «las relaciones intergeneracionales pueden procurar el sustrato del buen vivir en sociedad. La sabiduría de los adultos mayores, de la experiencia vital, debe ser compartida, pero también contrastada, con la plasticidad y la energía de los más jóvenes. El arte de vivir, el arte de amar, el arte de ser feliz no se puede entender ( $\mathrm{y}$ no se puede lograr) fuera de esos entramados de socialización profigurativa que, lejos de aceptar la ruptura generacional, promueven ese nuevo contrato entre generaciones ya que el cuidado deviene fundamental». (p.156).

El capítulo de conclusiones sintetiza las aportaciones del conjunto, mostrando una vez más un ejemplo de coherencia entre teoría y relato: «A lo largo de esta obra he ido recordando muchas de las ideas y consejos que he ido recibiendo de mis padres y que ha ido recibiendo la nieta de ellos, por ellos directamente o también de mi mismo, su padre, a la vez que ella nos enseñaba a los abuelos y a los padres cosas que desconocíamos y experiencias que eran nuevas para nosotros, así como actitudes que nos hacían ver de otra manera la propia vida». (p. 166).

Felicitamos al autor por el fondo y la forma, por las aportaciones científicas y humanas. La lectura deja una agradable sensación de bienestar intelectual y elementos para pensar sobre las múltiples posibilidades de trabajar con, y desde, la profiguración en el ahora mismo. «En pleno siglo xxi, podemos aunar etimología y modernidad y pensar que, si pasamos de nuevo por el corazón, podemos recordar y tener una memoria entrañable para seguir adelante, para construir un presente y un futuro mejor, de manera intergeneracional, de manera profigurativa». (p.167). Pensamos, por ejemplo, en pueblos y lugares de nuestra España despoblada — que no vaciada — en donde hasta las piedras te hablan, según la metáfora de Escudero 
(2020: 19). Esa poblada por abuelas y abuelos que mantienen la actividad, la historia pasada y presente en el bastión local casi en solitario. Desde la visión profigurativa son eslabones de unión y transmisión de conocimientos, experiencias y valores para las jóvenes generaciones en proyectos de repoblación y reasentamiento. Desde la misma visión, esas jóvenes generaciones, con sus conocimientos y aptitudes, son eslabones de enriquecimiento para los mayores. Sumas de mutuo valor para crear procesos de vida buena y de bienestar en una sociedad que queremos mejorada. Cerramos el libro y la reseña con la mejor frase posible, la del autor: «Concluimos como empezamos (...) con la invitación a vivir y a beber la vida a sorbos de felicidad, profiguración y amon». (p. 167).

\section{Referencias bibliográficas}

Asociación Internacional de Ciudades Educadoras, AICE (2020). Carta de Ciudades Educadoras. Disponible en https://www.edcities.org/carta-de-ciudades-educadoras/.

Escudero, Denis (2020). La España que abandonamos. Almeria: Circulo Rojo Editorial.

Molina-Luque, Fidel (2020a). La profiguración y la socialización Profigurativa: hacia unas relaciones sociales interdependientes e intergeneracionales. https://www.youtube.com/watch?v $=$ CTtIkGkrGoo.

Molina-Luque, Fidel (2020b): "The Art of Living as a Community: Profiguration, Sustainability and Social Development in Rapa Nui”. Sustainability, 12 (17), 67-98. DOI: https://doi.org/10.3390/su12176798.

Molina-Luque, Fidel (2019): “Profiguración’, acción creativa intercultural e innovación social: renovarse o morir en Rapa Nui (Isla de Pascua/Easter Island)". Revista Latinoamericana de Estudios sobre Cuerpos, Emociones y Sociedad RELACES, 29, 71-81.

Molina-Luque, Fidel (2017): “Calidad de vida y socialización profigurativa: consideraciones éticas sobre investigación en educación y en salud" en Fidel Molina-Luque y Montserrat Gea-Sánchez (coords.): Educación, Saludy calidad de vida. Nuevas perspectivas interdisciplinares e interculturales. Barcelona: Graó. 